\title{
Filipino and American Teachers: \\ Their Differences in Psychological Needs, Performance, and Culture
}

\author{
Mart Andrew S. Maravillas \\ The University of Southern Mississippi, United States \\ Email: m.maravillas@usm.edu \\ Address: 118 College Drive, \#5057 Hattiesburg, 39401 Mississippi, U.S.A.
}

\section{Background}

Filipino teachers have pervaded in the American K-12 school system as cited by news agencies whose articles about teacher migration made a voluminous list (Los Angeles Times 2009; The Guardian 2018; New York Times 2018; The Sydney Morning Herald 2018). Filipino teachers are among the 19,300 teachers who are trained overseas (American Federation of Teachers or AFT 2009, p. 10). The U.S. State Department reports that the number of Filipino teachers in the United States has increased to almost forty times over a decade through the exchange visitor exchange program alone (Yan, Chiaramonte, and Lagamayo 2019). Despite this remarkable surge, scientific inquiries that study to international teachers, much less Filipino teachers, remain stagnated and are almost non-existent. Though there are a few studies that discuss international teachers' challenges and difficulties which result to ineffective teaching, these accounts are somewhat dated and do not center on K-12 Filipino teachers (Dunn 2011; Finney, Torres, and Jurs 2002; Hutchinson 2005). This study focuses specifically on teachers who were born and who have had their teacher education in a higher education institution (HEI) in the Philippines and who are currently teaching in the United States as primary and secondary teachers. I refer to them as the Filipino international teachers.

Throughout the United States are reports of severe teacher shortages, especially for teachers who specialize in special education, math, science, and English for bilingual learners (Stutcher, Darling-Hammond, and Carver-Thomas 2016, p. 11). One cause for this shortage is that some teachers are deemed to not be "fully-prepared" for the teaching profession and who leave the profession at rates "two or three times as high [than those teachers] who have had 'comprehensive' preparations, teachers with substandard credentials were inevitably hired by some school districts" (Stutcher et al. 2016, p. 4). As a result, many districts in the US employ qualified teachers from overseas through the issuance of work and exchange visitor visas, known as the H1-B and J-1 visas, respectively (AFT 2009, p. 10-13). Currently, through the J-1 visa program, at least five hundred primary and secondary public schools in almost 20 states have hired Filipino teachers who have satisfied the standards (academic degrees, professional experience, and teaching license) of the state in which they are working (AFT 2009, p. 12; Sarmiento 2019). It is not clear, however, if the Filipino international teachers' psychological needs in terms of cultural preparation have been satisfied before arriving in the United States. Because the movement of teachers from abroad alleviates the US education crisis in terms of supply of educators (Startz 2017), the presence of overseas-trained teachers, especially the Filipinos, appears to persist in the future and may have an impact on the American youth. As such, it is therefore timely to more fully understand the needs of Filipino international teachers.

\section{Literature Review}


Gina Riley (2015, p.1) assessed "whether home schooled young adults' needs for competence, autonomy, and relatedness are better satisfied as compared to young adults who were not home schooled". Like Riley's, this study uses the self-determination theory as its lens when looking at the satisfaction of individuals' basic psychological needs (BPNs). However, this current study focuses on the Filipino international teachers. Riley's study focuses on intrinsic motivation as facilitated by satisfying one's needs of competence, autonomy and relatedness (Riley 2015, p. 21). This current researcher centers on positive outcomes on performance satisfaction as an effect of satisfying those psychological needs.

\section{Education and Psychological Needs}

According to the self-determination theory (SDT), an individual has three basic psychological needs (BPNs). According to Ryan and Deci (2017), these are the needs for autonomy, competence and relatedness that must be satisfied first to achieve positive development and well-being, and better performance (Yang, Zhang, and Sheldon 2018, p. 96). One study found that, overall, these needs are highly satisfied among educated young adults regardless of whether they are home or traditionally schooled (Riley 2015, p. 14). However, different types of education and educational environment do not necessarily satisfy each need equally (Orsini, Binnie, and Tricio 2018, p. 5; Riley 2015, p. 15). Literature has not addressed whether education in different cultural settings satisfies learners' BPNs equally and whether these needs are satisfied better with higher educational attainment level.

\section{Psychological Needs, Performance, and Well-being}

Several studies support the tenet of the SDT across cultures and life domains. In countries outside the United States, satisfaction of the BPNs are seen to promote better school performance outcomes among students in Portugal (Simeos and Alarcao 2014, p. 465) and in Spain (Carmona-Halty, Schaufell, Llorens, and Salanova 2019, p. 1). On work performance, fulfillment of BPN predicted Iranian employees' work satisfaction and job performance (Arshadi 2010, p. 1266). Most of these studies, however, have been conducted based on self-report and within the participants' cultural environment. Literature has not provided whether a change in cultural setting has a mechanism on the relationship between how much individuals have satisfied their psychological needs and how well they think they perform.

\section{Performance, Culture, and Psychological Needs}

Alyssa Hadley Dunn (2011) reported that among international teachers' difficulties was dealing with culture shock (p. 1384). Culture shock (usually occurs when an individual makes a transition between two different cultural settings) was seen to have negative impacts on one's happiness and satisfaction in life and on performance based on the recent literature review (Chen, Lin, and Sawangpattanakul 2011, p. 254; Yang et al. 2018, p. 95-96). Though their strongest suit is subject area content (Dunn 2011, p. 1400), international teachers find it challenging to convert this to effective teaching, perhaps, due to cultural differences. Filipinos are from a collectivist culture (Datu, Yuen, and Chen 2017, p.199). While they live and work in the United States, they are immersed in a culture opposite to theirs, an individualist culture (Fackrell, Galovan, Hill, and Holmes 2013, p.51; Gruber 2012, p.418). Individualist Americans tend to give more priority to their individual needs, goals, and preference while the collectivist Filipinos mostly prioritize those of others (Yang et al. 2018, p. 96). This transition to a different cultural setting may bring culture shock. It is necessary to determine how much culture shock the Filipino international teachers are experiencing and whether their culture shock affect their teaching performance.

\section{Research Problem}

Pursuant to Dunn's recommendation (2011, p. 1402), this current study focuses on the Filipino teaching population in the United States, specifically in the K-12 education system. To address the gap in the literature, this study seeks to answer the following questions: 
RQ1. Are there statistically significant differences between Filipino international teachers (overseas-trained) and American teachers (US-trained) in terms of their perceived a) psychological needs satisfaction, and b) performance satisfaction?

RQ2. Are teachers' BPNs equally satisfied regardless of which cultural settings they have had their teacher education?

RQ3. Does higher educational attainment level correlate with higher BPNs satisfaction?

RQ4. Among Filipino international teachers, does the fulfillment of their BPNs correlate with performance satisfaction?

RQ5. Does Filipino international teachers' experience of culture shock have a mediating or moderating effect on the relationship between the satisfaction of their BNP and performance satisfaction?

\section{Methodology}

This study is a quantitative comparison between Filipino international teachers and American teachers in terms of the levels of BPNs fulfillment and performance satisfaction. Among the Filipino international teachers, within-group analyses will be done regarding educational attainment and psychological needs satisfaction, and performance satisfaction and culture shock.

\section{Participants}

The targeted populations in this study are Filipino international teachers and American teachers. I will only recruit participants who are 18-30 years old and who have standard teaching license recognized by the United States. Since the exact number of Filipino international teachers cannot be ascertained and whose location cannot be easily identified, I intend to use non-probabilistic sampling technique. The questionnaires will be given to Filipino international teachers whom I know. I will ask them to refer another Filipino teacher and an American colleague in the same school. Through the snowball sampling techniques, I will gather volunteers in various school districts in different states in the US.

\section{Measures}

Higher education. The participants will be asked to indicate their highest educational attainment level and whether they have been educated in the Philippines or in the United States.

Satisfaction of Psychological Needs. The 16-item Balanced Measure of Psychological Needs (BMPN) developed by Sheldon and Hilpert which has features where, when the need arises, separate analyses on autonomy, competence, and relatedness with respect to teacher education are possible $(2012$, p. 449). Separate analyses will allow the researcher to see how much higher education training impact the satisfaction of each psychological need.

Culture Shock. The 12-item version of the culture shock questionnaire (CSQ) developed by Mumford will be used which was found to have the highest reliability among others (1998, p.153).

Performance. The researcher did not find any universal instrument that measures teachers' performance. The Teaching Satisfaction Scale cannot be employed here because it only measures how satisfying teaching is as perceived by teachers (Ho and Au 2006, p. 182). It does not measure how content teachers are with their performance. Therefore, in this study, each teacher will be asked to respond to this prompt, "Please rate how satisfied you currently are with your performance as a teacher." This item was adapted by Nicholls, Polman, and Levy (2012, p. 266) when they asked athletes to rate how satisfied they were on their sporting performance.

\section{Data analysis}

To answer RQ1, a multivariate analysis of variance will be used to determine whether the (a) BPNs are equally satisfied and (b) levels performance satisfaction are equal between the two groups of teachers. 
To answer RQ2 and RQ3, Pearson's chi-square test of independent will be used to determine whether the level of satisfaction of BPNs is associated with (RQ2) the difference in HEI cultural setting and (RQ3) the educational attainment level.

To answer RQ4, Pearson's rho correlation will be used to determine the relationship between the Filipinos' satisfaction of their BPNs and performance satisfaction.

To answer RQ5, a linear regression analysis will be used to determine whether culture shock has a mechanism on the relationship between fulfillment of BPNs and performance satisfaction among Filipino international teachers.

\section{Acknowledgement}

The author acknowledges the encouragement and guidance provided by Dr. Thomas O'Brien and thanks to Dr. Maria Conti Maravillas, my wife, though had unloving comments, but still remains lovable.

\section{References}

American Federation of Teachers. 2009. "Importing Educators: Cases and Consequences of International Teacher Recruitment." 1-45. https://www.aft.org/sites/default/files/importingeducators_2009.pdf.

Arshadi, Nasrin. 2010. "Basic Need Satisfaction, Work Motivation, and Job Performance in an Industrial Company in Iran." Procedia Social and Behavioral Sciences 5: 1267-1272.

Carmona-Halty, Marcos, Wilmar B. Schaufeli, Susana Llorens, \& Marisa Salanova. 2019. "Satisfaction of Basic

Psychological Needs Leads to Better Academic Performance via Increased Psychological Capital: A Three-Wave Longitudinal Study Among High School Students." Frontiers in Psychology 1(2113): 1-5.

Chen, Angela Shin-yih, Yi chun-Lin, \& Airin Sawangpattanakul. 2011. "The Relationship Between Cultural Intelligence and Performance with the Mediating Effect of Culture Shock: A Case From Philippine Laborers in Taiwan." International Journal of Intercultural Relations 35(2): 246-258.

Datu, Jesus Alfonso D., Mantak Yuen, \& Gaowei Chen. 2017. "Development and Validation of the Triarchic Model of Grit Scale (TMGS): Evidence From Filipino Undergraduate Students." Personality and Individual Differences 114: 198-205.

Dunn, Alyssa Hadley. 2011. "Global Village Versus Culture Shock: The Recruitment and Preparation of Foreign Teachers for U.S. Urban Schools.” Urban Education 46(6): 1379-1410.

Fackrell, Tamara, Adam M. Galovan, E. Jeffrey Hill, \& Erin Kramer Holmes. 2013. "Work-Family Interface for Married Women: A Singapore and United States Cross-Cultural Comparison." Asia Pacific Journal of Human Resources 51(3): 347-363.

Finney, Pamela, Torres, Jess, \& Jurs, Stephen. 2002. “The South Carolina/Spain Visiting Teacher Program.” Clearing House 76(2): 94-97.

Goldstein, Dana. "Teacher Pay Is So Low in Some U.S. School Districts That They're Recruiting Overseas." The New York Times. May 2, 2018. https://www.nytimes.com/2018/05/02/us/arizona-teachers-philippines.html.

Gruber, Craig. 2012. "Culture, Courage and Collectivism: An Insider's Guide to Culture in American Schools." Culture and Psychology 18(3): 417-424.

Ho, Chung-Lim \& Wing-Tung Au. 2006. "Teaching Satisfaction Scale: Measuring Job Satisfaction of Teachers." Educational and Psychological Measurement 66(1): p.172-185.

Hutchinson, Charles. 2005. "Teaching in America: A Cross-Cultural Guide for International Teachers and Their Employers.” Dordrecht, Netherlands: Springer. 
Milyavskaya, Marina, \& Richard Koetner. 2011. "Psychological Needs, Motivation, and Well-Being: A Test of SelfDetermination Theory Across Multiple Domains." Personality and Individual Differences 50(3): 387-391.

Mumford, D. B. 1998. "The Measurement of Culture Shock." Social Psychiatry and Psychiatric Epidemiology 33(4): 149-154.

Nicholls, Adam R., Remco C.J. Polman, \& Andrew R. Levy. 2012. "A Path Analysis of Stress Appraisals, Emotions, Coping, and Performance Satisfaction Among Athletes." Psychology of Sport and Exercise 13(3): 263-270.

Olding, Rachel. "The Immigrant Teachers Coming to US Schools Under Trump's Nose." The Sydney Morning Herald.

March 10, 2018. https://www.smh.com.au/world/north-america/the-immigrant-teachers-coming-to-us-schoolsunder-trump-s-nose-20180227-p4z1vd.html.

Orsini, Cesar A., Vivian I. Binnie, \& Jorge A. Tricio. 2018. "Motivational Profiles and Their Relationships with Basic Psychological Needs, Academic Performance, Study Strategies, Self-Esteem, and Vitality in Dental Students in Chile." Journal of Educational Evaluation for Health Professionals 15:11.

Riley, Gina. 2015. "Differences in Competence, Autonomy, and Relatedness Between Home Educated and Traditionally Educated Young Adults." International Social Science Review 90(2): 1-27.

Sheldon, Kennon M., \& Jonathan C. Hilpert. 2012. "The Balanced Measure of Psychological Needs (BMPN) Scale: An Alternative Domain General Measure of Need Satisfaction." Motivation and Emotion 36(4): 439-451.

Shogren, Karrie A., Jaehoon Lee, \& Pavel Panko. 2017. "An Examination of the Relationship Between Postschool Outcomes and Autonomy, Psychological Empowerment, and Self-Realization" The Journal of Special Education 51(2): 115-124.

Simeos, Francisco, \& Madalena Alarcao. 2014. "Mentors and Teachers: Testing the Effectiveness of Simultaneous Roles on School Performance from a Basic Psychological Needs Perspective." Instructional Science 42(3): 465483.

Startz, Dick. "Immigrant Teachers Play a Critical Role in American schools." Brookings. March 16, 2017. https:/www.brookings.edu/blog/brown-center-chalkboard/2017/03/16/immigrant-teachers-play-a-critical-role-inamerican-schools/.

Sterling, Terry Greene, \& Joffe-Block, Jude. "The Job Americans Won't Take: Arizona Looks to Philippines to Fill Teacher Shortage." The Guardian. September 5, 2018. https://www.theguardian.com/usnews/2018/sep/05/arizona-teachers-filipino-schools-low-pay.

Sutcher, Leib, Darling-Hammond, Linda, \& Carver-Thomas, Desiree. 2016. "A Coming Crisis in Teaching? Teacher Supply, Demand, and Shortages in the U.S." Learning Policy Institute. https://learningpolicyinstitute.org/sites/default/files/product-files/A_Coming_Crisis_in_Teaching_REPORT.pdf.

Watanabe, Teresa. "Filipino Teachers Exchange Homeland for Jobs in America." Los Angeles Times. March 18, 2009. https:/www.latimes.com/archives/la-xpm-2009-mar-18-me-filipino18-story.html.

Yan, Holly, Chiaramonte, Tiara, \& Lagamayo, Anne. "Desperate to Fill Teacher Shortages, US Schools are Hiring Teachers from Overseas." CNN. October 6, 2019. https://cnnphilippines.com/world/2019/10/6/united-statesteacher-shortage-philippines.html?fbclid=IwAR0rrt6mAx-

OB0qNxERjSyiYBz2yPmLlyx3uUWJUNHx_dJ1W80DagjgMofk?fbclid.

Yang, Ying, Yixin Zhang, \& Kennon M. Sheldon. 2018. "Self-Determined Motivation for Studying Abroad Predicts Lower Culture Shock and Greater Well-Being Among International Students: The Mediating Role of Basic Psychological Needs Satisfaction." International Journal of Intercultural Relations 63: 95-104. 